\title{
A METÁFORA DA OPRESSÃO E DA LIBERDADE EM HAROUN E O MAR DE HISTÓRIAS
}

(The metaphor of oppression and freedom in "Haroun and the sea of stories")

\author{
Silas Rodrigues Machado ${ }^{1}$ \\ Universidade da Integração Latino-Americana - Unila \\ Mariana Cortez ${ }^{2}$ \\ Universidade da Integração Latino-Americana - Unila
}

\section{RESUMO}

O objetivo deste artigo é analisar a obra Haroun e o Mar de Histórias, de Salman Rushdie (1998), a partir da oposição opressão versus liberdade. A Semiótica Discursiva formulada por A. J. Greimas norteará a análise. Pretende-se revelar, a construção de sentido de uma obra marcada pela imposição da censura em oposição à liberdade de expressão. Para isso, apoiamo-nos nas elucidações da teoria realizadas por José Luiz Fiorin (2013; 1999; 1995), Diana Luz Pessoa de Barros (2008; 2002; 1994) e Luiz Tatit (2014) e os encaminhamentos sobre a relação entre o discurso e o contexto explicados por M. Bakhtin (2000).

Palavras-chave: Censura. Liberdade. Discurso. Semiótica.

\begin{abstract}
The purpose of this paper is to analyze Haroun and Sea of Stories, by Salman Rushdie (1998), from the oppression versus freedom opposition. The Discursive Semiotics formulated by A. J. Greimas will guide the analysis. It is intended to reveal, the construction of meaning of a work marked by the imposition of censorship as opposed to freedom of expression. To that end, we support the elucidations of the theory made by José Luiz Fiorin (2013, 1999, 1995), Diana Luz Pessoa de Barros (2008, 2002, 1994) and Luiz Tatit (2014) and the referrals about the relation between discourse and the context explained by M. Bakhtin (2000).
\end{abstract}

Keywords: Censorship. Liberty of expression. Discourse. Semiotics.

Recebido em: janeiro 2019

Aceito em: fevereiro 2019

DOI: $10.26512 /$ les.v20i1.22395

Palavra quando acesa

Não queima em vão

Deixa uma beleza posta em seu carvão

E se não lhe atinge como uma espada

Peço não me condene oh minha amada

(Fernando Filizola)

\footnotetext{
${ }^{1}$ Mestrando em Literatura Comparada pela Universidade Federal da Integração Latino-Americana e Bolsista PPGLC/UNILA. E-mail: machadosilasr@gmail.com

${ }^{2}$ Docente no Mestrado de Literatura Comparada na Universidade Federal da Integração Latino-Americana. Doutora em Letras pela Universidade de São Paulo. E-mail: mariana.cortez@unila.edu.br
} 


\section{INTRODUÇÃO}

Quase 30 anos se passaram desde que Salman Rushdie recebeu o fatwa - sentença de morte promulgada pelo líder fundamentalista islâmico iraniano aiatolá Khomeini - por escrever o romance Versos Satânicos (1988), em que condena o Islamismo por perseguir cristãos e hindus. A sombra do ocorrido ainda o persegue e se revela em sua produção literária. Em entrevistas posteriores à publicação de Haroun e o Mar de Histórias (1990), o autor afirma que seu livro é uma tentativa de explicar ao filho o que é a liberdade de expressão em um contexto de censura.

Tendo em vista esse contexto, a análise proposta preocupa-se, fundamentalmente, em pontuar os mecanismos que engendram e constituem o sentido da obra Haroun e o Mar de Histórias, de Rushdie, fundamentados pelas proposições da Semiótica Discursiva inicialmente desenvolvida por A. J. Greimas e seus colaboradores e que encontra terreno fértil nas reflexões analítico-teóricas dos brasileiros Diana Luz Pessoa de Barros (2008; 2002; 1994), José Luiz Fiorin (2013; 1999; 1995) e Luiz Tatit (2014).

Como ponto de partida para análise, destaca-se a oposição fundamental entre opressão versus liberdade, partindo, no percurso gerativo de sentido, do mais simples e abstrato para o mais complexo e concreto no nível do discurso. Nesta superfície discursiva, já com os investimentos semânticos expressos, instala-se a oposição figurativa silêncio versus palavra. Com o objetivo de demonstrar o funcionamento de ditas oposições, primeiramente, lançaremos atenção ao percurso narrativo do protagonista Rashid, o Mar de Histórias ou o Xá do Blablablá, que já em suas duas designações impõem uma polêmica entre aqueles que o entendem como "Blablablá" e aqueles que o nomeiam como "Mar de Histórias".

Dessa forma, a partir do percurso gerativo de sentido proposto como "simulacro do mundo", almeja-se compreender o enunciado e seus efeitos de sentido, para estabelecer relações com os anseios, os temores e as expectativas de um tempo-espaço pertencentes a um determinado grupo social, discutindo o texto como objeto de comunicação e de significação.

Entendemos que, assim como o tecelão, o qual, por meio do tear, enlaça o tecido com fios, tramados horizontal e verticalmente, Rushdie tece um texto entrelaçando as muitas histórias presentes no nosso imaginário, transformando uma narrativa fantástica em uma obra cheia de referências, que fala sobre o próprio ato de criar textos.

\section{1. À LUZ DA TEORIA E DOS FIOS}

Sabemos que a análise do texto não restringe apenas a fios ou palavras soltas, mas sim a sua totalidade de sentido. Da mesma forma que um tecido não é um amontoado desorganizado de 
fios, "o texto não é um amontoado de frases, nem uma grande frase. Tem ele uma estrutura, que garante que o sentido seja apreendido em sua globalidade, que o significado de cada uma de suas partes dependa do todo" (FIORIN, 1995, p. 1). De acordo com Barros (2002, p. 7), define-se o texto a partir de duas formas que se complementam: objeto de significação e objeto de comunicação. A primeira concepção de texto, que remete à estruturação ou organização - a qual o tece como uma totalidade de sentido -, se tem atribuído o nome de "análise interna ou estrutural do texto", que muitas vezes é confundido com o exame dos procedimentos e mecanismo estruturantes. A segunda caracterização, denominada como "análise externa do texto", já não o toma como objeto de significação, mas como objeto de comunicação entre dois sujeitos, em que o texto será examinado em relação ao contexto sócio-histórico que o envolve.

[...] o texto só existe quando concebido na dualidade que o define - objeto de significação e objeto de comunicação - e, dessa forma, o estudo do texto com vistas à construção de seu ou de seus sentidos só pode ser entrevisto como o exame tanto dos mecanismos internos quanto dos fatores contextuais ou sócio-históricos de fabricação do sentido. Nos seus desenvolvimentos mais recentes a semiótica tem caminhado nessa direção e procurado conciliar, com o mesmo aparato teóricometodológico, as análises ditas 'interna' e 'externa' do texto. Para explicar 'o que o texto diz' e 'como o diz', a semiótica trata, assim, de examinar os procedimentos da organização textual e, ao mesmo tempo, os mecanismos enunciativos de produção e de recepção do texto (BARROS, 2002, p. 8).

Conforme analisa Fiorin, a Semiótica concebe-se como uma teoria gerativa, sintagmática e geral: “É uma teoria sintagmática, porque seu escopo é estudar a produção e a interpretação dos textos. É geral, porque se interessa por qualquer tipo de texto, independentemente de sua manifestação" (1995, p. 166). Segundo o autor, a teoria se baseia na ideia de que o conteúdo pode ser analisado separadamente da expressão, pois o mesmo conteúdo pode ser representado por diferentes expressões - verbal, visual, sonora etc. Sob essa óptica, a Semiótica sugere que para explicar o ou os sentidos do texto, deve-se primeiro atentar-se ao plano do conteúdo e ensina que para examiná-lo, “faz abstração da manifestação [...] e só depois vai estudar as especificidades da expressão e sua relação com o significado" (FIORIN, 1995, p. 167).

No caso do presente estudo, não buscaremos apenas compreender o que o texto Haroun e o Mar de Histórias diz, mas também, pretendemos entender como ele faz para dizer. Para atingir a este objetivo, o encaminhamento metodológico proposto pela Semiótica ilumina o processo, pois concebe o plano do conteúdo do texto como um percurso gerativo de sentido, que parte do mais simples e abstrato (nível fundamental) ao mais concreto e complexo (nível discursivo), além de indicar como se estabelece a organização narrativa com seus contratos entre destinatários e destinadores (sujeitos), que partilham ou disputam objetos valor. 


\section{NÍVEL FUNDAMENTAL: OPRESSÃO E LIBERDADE}

A primeira etapa do percurso gerativo de sentido recebe o nome de nível fundamental ou das estruturas fundamentais. Luiz Tatit (2014) explica que a Semiótica desenvolvida por Greimas prevê o que poderíamos chamar de solução vertical, uma perspectiva gerativa, na qual as unidades manifestadas na superfície do texto seriam elementos já enriquecidos, "provenientes da articulação entre categorias mais simples e abstratas localizadas em patamares mais profundos que só o procedimento descritivo pode revelar" (TATIT, 2014, p. 188). Sendo assim, o primeiro passo desse procedimento é "determinar a oposição ou as oposições semânticas a partir das quais se constrói o sentido do texto" (BARROS, 2002, p. 10). Essas categorias semânticas caracterizadas por uma oposição binária são base de qualquer texto e se manifestam de diversas formas. Tais oposições ganham o valor de positivas - eufóricas - e negativas - disfóricas. Cabe ressaltar que ser determinado como positivo ou negativo modifica-se de acordo com os valores presentes; não é sempre que a categoria "vida" ganha o valor positivo e "morte" o valor negativo, por exemplo: se em uma história, morte for metáfora para libertação, pode ganhar o valor positivo, como nos esclarece Barros (2008).

Enlaçando a teoria à obra de Rushdie, o personagem Rashid Khalifa é um célebre contador de histórias conhecido como o Mar de Ideias, por aqueles que valorizam a imaginação e o Xá do Blablablá, para os que não gostam de histórias. Um dia, a esposa do contador de histórias, Soraya, abandona-o para fugir com o vizinho Senhor Sengapura, que, para ela, não tem imaginação e vive na realidade, não ter imaginação para Soraya é algo positivo. Depois da desilusão da separação, o protagonista é convidado para fazer duas apresentações para políticos - uma na Cidade $G$ e outra no vizinho Vale de $K$-, e para superar o choque do abandono, convida Haroun - seu único filho - para viajar com ele. No meio da primeira apresentação, o impensável acontece, o festejado Mar de Ideias abre a boca e a única coisa que sai dela é um Aak. Na noite anterior à segunda apresentação, já aterrorizado com a possibilidade de fracasso, o contador de histórias começa a se questionar sobre a pertinência de exercer seu ofício em um contexto tão adverso. Em um momento de desespero, decide desistir de tudo, aposentar-se, cancelar sua "assinatura", ato que alimenta a sua imaginação. Rashid conta a Haroun sobre sua ligação com o Mar de fios de Histórias e ele decide recuperar o dom de seu pai, ou seja, reconectá-lo com a maior biblioteca do universo, partindo para uma viagem fantástica em busca das palavras e desafiando forças terríveis como a escuridão e o silêncio.

Haroun e o Mar de Histórias se constitui pela oposição semântica fundamental: opressão versus liberdade. Segundo Fiorin (1995), os textos podem "trabalhar com a mesma categoria semântica, mas axiologizá-la diferentemente e isso vai produzir discursos completamente distintos" 
(1995, p. 168). Dessa forma, as categorias fundamentais apresentadas por Rushdie produzem dois tipos de discursos coexistentes na história. No primeiro, sob a ótica dos que chamam Rashid de Mar de Histórias e entendem como positivo o fato de ele ter habilidade para contar histórias, o contador de histórias é tão valorizado, que é contratado para fazer campanha para os políticos. Apesar de Mar de Histórias ser um investimento figurativo, se ele for abstraído, no nível fundamental, seria a categoria liberdade, pois dará forma à liberdade de expressão, como será demonstrado posteriormente. Já sob a segunda perspectiva, podemos identificar um discurso que nega as histórias de Rashid e o chamam de Xá do Blablablá, neste caso, a palavra é disfórica. Subjacente, portanto, as designações Mar de Histórias versus Xá do blábláblá estão a oposição fundamental liberdade versus opressão como oposições estruturantes do sentido do texto. A obra propõe um percurso da opressão (disforia) - não opressão (não disforia) - liberdade (euforia).

A chave dada pela designação de Rashid autoriza a leitura da opressão como o silêncio do personagem e a liberdade como a possibilidade de exercer seu ofício, já que tem o poder da palavra. Podemos entender que a obra em questão tem dois protagonistas - Rashid e Haroun - e o título da obra recupera essa hipótese. Para fundamentarmos a opção pela oposição, podemos observar novamente a caracterização de Rashid que terá implicações no posicionamento de Haroun, já que eles passam da palavra positiva ao silêncio negativo e da palavra negativa ao silêncio positivo.

Rashid, o Mar de Histórias e Haroun:

Palavra
(euforia) $\rightarrow \quad \begin{aligned} & \text { não palavra } \\ & \text { (não-euforia) }\end{aligned} \rightarrow \quad \begin{gathered}\text { silêncio } \\ \text { (disforia) }\end{gathered}$

Rashid, o Xá do Blablablá e Haroun:

Palavra
(disforia) $\rightarrow \quad \begin{aligned} & \text { não palavra } \\ & \text { (não disforia) }\end{aligned} \quad \rightarrow \quad \begin{aligned} & \text { silêncio } \\ & \text { (euforia) }\end{aligned}$

Esse percurso entre os termos pode ser mais bem visualizado quando representado topologicamente pelo quadrado semiótico. Luiz Tatit argumenta que tal quadrado

[...] prevê uma sintaxe sumária que consegue apreender em seus termos - desde que bem escolhidos - não só os estados narrativos, mas especialmente suas transformações. Para tanto, conta basicamente com as operações de negação e asserção. Com a primeira, instaura os termos contraditórios que, muitas vezes, funcionam como termos de passagem. Com a segunda, instaura os termos contrários que articula a principal oposição contida num texto (TATIT, 2014, p. 198). 
Nesse sentido, essas oposições ganham uma representação visual da articulação lógica de uma categoria semântica, que permite visualizar a dinamicidade narrativa presente no texto: quando negamos a um termo, temos a asserção de outro, estabelecendo uma espécie de percursividade. No nosso caso, ficaria da seguinte forma:

\section{Flecha na horizontal, relação entre contrários}

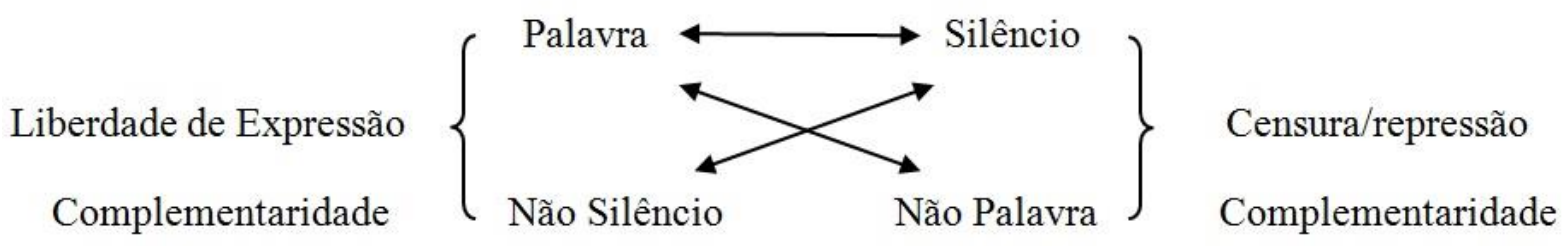

Flecha na diagonal, relação entre contraditórios

Negando-se cada um dos termos da oposição temos um não termo, como: não palavra versus não silêncio. Os termos palavra versus silêncio mantêm entre si uma relação de contrariedade, ou seja, a palavra é contrária ao silêncio. $\mathrm{O}$ mesmo acontece com os termos não palavra versus não silêncio. Entre palavra e não palavra e silêncio e não silêncio há uma relação de contraditoriedade. Ademais, palavra e não silêncio, assim como silêncio e não palavra, estabelecem uma relação de complementariedade e, com efeito, temos como resultado da primeira relação, a liberdade de expressão - eufórico - e da segunda, a censura/repressão - disfórico.

No que tange a narrativa, temos: asserção da palavra, negação da palavra e asserção do silêncio e, o segundo momento: asserção do silêncio, negação do silêncio e asserção da palavra. Segue o detalhamento:

A) Asserção da palavra: Rashid é o famoso Mar de História, um festejado contador de histórias profissional, que possui o dom da palavra (ligação com o Mar de Fios de histórias); negação da palavra: sua esposa Soraya, Sr. Sengapura e até Haroun, o questionam sobre a utilidade de suas histórias, que nem são de verdade; asserção do silêncio: Rashid nega as histórias, tem um bloqueio criativo e cancela sua assinatura com o Mar de Fios de Histórias.

B) Asserção do silêncio: Rashid não consegue mais contar histórias, agora é o silêncio que predomina; negação do silêncio: Haroun nega a desconexão de seu pai com o Mar de Fios de Histórias e viaja ao país de Gup para tentar corrigir o cancelamento; asserção da palavra: depois de sua aventura consegue fazer com que seu pai volte a contar histórias.

\section{NÍVEL NARRATIVO: EM BUSCA DA LIBERDADE}

Retomando as teorias da narrativa, Barros (2008, p. 191) afirma que: 
A narrativa de um texto é a história de um sujeito em busca de valores. Para que o sujeito tenha acesso aos valores, são eles inscritos nos objetos. Os objetos, com seus valores, circulam entre sujeitos. Dessa forma, quando um sujeito ganha ou adquire um valor, um outro sujeito doa esse valor ou é dele privado.

Alicerçados por essa explicação, constatamos que o texto em análise é complexo e polêmico do ponto de vista narrativo, já que a história narrada é a de Rashid que está conjunto com o objeto valor "contar histórias" (liberdade), mas que pela manipulação exercida pela esposa que o trai, torna-se disjunto de seu valor e, portanto, oprimido pelo silêncio. Haroun não entende o que se passa, mas quer ver seu pai feliz e estabelecer novamente sua família, então, parte em busca de um “saber-fazer" para "poder-fazer" sua performance ação e transformar o estado de seu pai.

Haroun terá seu percurso de aquisição de competência para, em seguida, doá-la a Rashid. O percurso narrativo do filho é de aprendizagem, pois terá de enfrentar aventuras para atingir seu objetivo e adquirir competência para transformar o estado do pai.

Vale destacar os diferentes investimentos figurativos que representam essa oposição: a habilidade de contar histórias de Rashid versus a privação dessa habilidade; Rashid versus Senhor Sengapura; o Mar de Fios de Histórias versus o veneno que mata as histórias; o rei Chattergy que permite toda forma de manifestação versus o tirano Khattam-Shup, que proíbe qualquer forma de ruído; o exército Pajens-Páginas - o livro como forma de poder versus os Tchupwalas - que são obrigados a costurar as próprias bocas e, também, o país de Gup versus o país de Tchup, que são a própria representação desses opostos, já que no primeiro reina o dia, o barulho, as histórias, o calor, etc. e, no segundo, a noite, o silêncio, o ódio às histórias, o frio, etc..

Em Haroun e o Mar de Histórias, há duas transformações, para entendê-las, analisaremos o seguinte trecho:

E foi aí que aconteceu aquilo: Algo Impensável. Rashid subiu no palco diante daquela floresta de gente e Haroun ficou olhando dos bastidores laterais. O pobre contador de histórias abriu a boca e a multidão deu gritinhos excitados; e agora Rashid Khalifa, em pé lá na frente, de boca aberta, descobriu que sua boca estava tão vazia quanto seu coração (RUSHDIE, 1998, p. 26).

Identificamos no trecho que Rashid possui o dom da palavra, isto é, está em relação de conjunção com a liberdade em seu estado inicial. Em seguida, passa a estar disjunto do objeto valor, quando o sujeito surpreende a multidão com sua boca vazia e, decorrente disso, figurativiza-se a transformação de estado. Rashid passa de um estado inicial conjunto para um estado final disjunto da liberdade/palavra. Essa mudança de estado acontece graças ao percurso pressuposto da manipulação, em que a esposa Soraya abandona o marido e com isso "rouba-lhe" a palavra (liberdade) e impõe-lhe o silêncio. Dessa forma, Rashid entra em contato direto com os valores do 
silêncio manipulado por Soraya, que antes de abandoná-lo deixa a seguinte carta: "você só se interessa pelo prazer, mas um homem decente deve saber que a vida é uma coisa séria. Seu cérebro está cheio de faz-de-conta, não tem lugar para a realidade” (RUSHDIE, 1998, p. 20). Soraya, por sua vez, fora manipulada pelo Senhor Sengapura, que crítica o sujeito Rashid por viver no mundo da lua e não ter os pés no chão: “Afinal de contas, o que são essas histórias todas? A vida não é nenhum livro de histórias, nem uma loja de piadas. Todo esse divertimento ainda vai acabar mal! E pra que servem histórias que nem sequer são de verdade?” (RUSHDIE, 1998, p. 16-17).

Já Haroun, o filho, ouve a conversa entre seus pais e ao ser abandonado pela mãe, reproduz aos gritos a fala do Senhor Sengapura dirigidos ao seu pai. O percurso pressuposto de Haroun se dá por não entender por que repetiu esse discurso, percebemos que o que o manipula é o abandono (amor pela mãe) e a tristeza (amor pelo pai). Como assevera Barros, "os elementos das oposições semânticas são assumidos como valores por um sujeito e circulam entre sujeitos, graças à ação também de sujeitos [...] não se trata mais de afirmar ou de negar conteúdos [...], mas de transformação, pela ação do sujeito" (2002, p. 11) sendo assim, o foco não é assegurar a palavra liberdade de expressão - e recusar o silêncio - a censura -, mas transformar, pela ação do sujeito, estados. No percurso de Haroun, que é de aquisição de competência, ele terá de fazer-se conjunto ao saber (a importância da palavra) para agir sobre o estado do pai.

Enquanto Rashid sofre pela ausência de histórias, dado seu estado de disjunção com a liberdade, ele depara-se com o sujeito MasDemais, um político que o contratou para contar histórias. MasDemais, por ter sua imagem corrompida pelas histórias contadas por seus inimigos, exige que Rashid conte apenas histórias alegres e elogiosas sobre ele durante o comício. Com isso, cria-se uma nova barreira em Rashid:

[...] 'Eu sou o Mar de Ideias, não sou nenhum Office-boy para ficar recebendo ordens! Mas não, que bobagem é essa! Vou subir no palco e não vou encontrar nada na minha boca, nadinha, só um aak. E aí eles vão me picar em pedacinhos, vai ser o meu fim! Finito, kaput, khattam-shud! É melhor eu parar de me iludir, desistir de tudo, me aposentar, cancelar minha assinatura. A mágica desapareceu, acabouse pra sempre depois que ela foi embora'. (RUSHDIE, 1998, p. 58).

Analisando o trecho, percebemos que o protagonista está com sua liberdade de escolha suprimida, ele não apenas acha que não pode contar histórias por acreditar que a "mágica" desapareceu, depois que Soraya o abandonou, mas também acredita que não deve, pois é pressionado a contar histórias para engrandecer políticos. Ele percebe, então, em um jogo veridictório, de um lado a verdade das histórias e, de outro, as mentiras dos políticos e se questiona sobre a pertinência de ter seu ofício corrompido. Contudo, aceita, neste primeiro momento, a 
manipulação do não poder não fazer dos manipuladores, apesar de não poder, crê que não deve contar a história encomendada pelo sujeito MasDemais, porém sua condição o "obriga".

Acompanhando a explicação de Fiorin (1995, p. 169), na fase da competência "um sujeito atribui a outro um saber e um poder fazer", fazendo do sujeito Rashid o grande contador de histórias, que nunca repete uma palavra, não é apenas seu dom/motivação, mas a relação sujeito/objeto figurativizado por Rashid/Mar de Fios de Histórias, pois ele sabe que está conjunto com a liberdade (Mar de Histórias), por ter o segredo do Mar do fio de Histórias. O protagonista acredita neste universo e isso lhe dá competência para o seu fazer. O objeto "mágico" (Mar de Fios de Histórias) é responsável por dar um saber e um poder fazer para o sujeito que realiza uma "assinatura". Depois da desilusão, Rashid acredita que é melhor cancelar a assinatura com o Mar de Histórias. A partir dessa disjunção, Haroun inicia seu percurso com o objetivo de relegar o pai ao universo das histórias.

Passa-se então para a fase da performance, nela "ocorre a transformação principal da narrativa" (FIORIN, p. 169). Rashid, manipulado por Haroun, deixa o que poderia ser entendido como o mundo "real" e viaja para um mundo de fantasias, o lugar de onde vêm todas suas histórias. Lá, no processo de enfrentar as forças ocultas do silêncio, entra em contato com outros valores, como os da liberdade de expressão e o poder da palavra. Nesse processo, mesmo estando numa batalha contra o silêncio, ainda tem dúvida quanto à força da palavra. Essa dúvida pode ser observada no início do confronto entre os Pajens-Páginas e os Tchupwalas.

Os páginas de Gup, agora que já tinham discutido tudo minuciosamente, lutavam duro, permaneciam unidos, apoiavam uns aos outros quando necessário, e pareciam, de modo geral, uma equipe com um objetivo comum. Toda aquela abertura, todos aqueles debates e discussões tinham criado entre eles poderosos laços de camaradagem. Os Tchupwalas, por outro lado, iam se revelando uma multidão desunida [...] muitos tinham que lutar contra suas próprias sombras traiçoeiras! [...] seu voto de silêncio e o hábito de manter tudo em segredo os faziam desconfiar e suspeitar do outro (1998, p. 223).

Rashid, ao perceber o esforço de seu filho em reativar sua assinatura com o Mar de Histórias e ver a vitória da palavra frente ao silêncio, dá um primeiro passo em direção à conjunção com a palavra. Após superar seu estado de silêncio (não contar histórias), finalmente, reativa a ligação com o objeto mágico que lhe permite fazer. Como consequência, Rashid assume o valor da liberdade. Mas dessa vez, de forma equilibrada. A presença do equilíbrio é manifestada de forma bem sutil ao longo da obra. Como na reflexão de Haroun sobre as oposições e a dança do Guerreiro das Sombras: 
'Mas a coisa não é assim tão simples', pensou consigo, pois a dança do Guerreiro da Sombra mostrou-lhe que o silêncio também tinha sua graça e beleza (assim como a fala pode ser feia e deselegante), e que a Ação podia ser tão nobre como as Palavras; e que as criaturas da noite podiam ser tão belas como os filhos da luz. 'Se os Gupis e os Tchupwalas não se odiassem tanto', pensou ele, 'poderiam descobrir que o outro lado é bem interessante. Dizem que os opostos se atraem' (RUSHDIE, 1998, p. 147).

Sugerindo que mesmo a palavra recebendo o valor positivo, deve-se buscar o equilíbrio; e é essa a grande transformação pela qual Rashid passa. Ainda, conforme Fiorin (1995, p. 169), a sanção pode ser cognitiva - em que há o reconhecimento por um sujeito de que a performance foi executada - e a pragmática - que pode ser manifestada por um prêmio ou castigo. No caso da obra analisada, acreditamos que a sanção se manifesta das duas formas. Defendemos tal ideia, pois a performance desenvolvida pelo protagonista é reconhecida tanto pelo reino de Gup que reativa sua assinatura quanto por Haroun e Soraya que aceitam o valor da palavra novamente. Além disso, em sua última apresentação, o senhor do silêncio é enfim derrotado, o político corrupto foge da apresentação sob vaias e o Senhor Sengapura é abandonado por Soraya. Assim, Rashid torna-se conjunto ao objeto valor liberdade e esta liberdade devolve a família de Haroun.

\section{NÍVEL DISCURSIVO: REATANDO LAÇOS}

O terceiro nível é o do discurso ou das estruturas discursivas, nessa etapa, os textos “devem ser examinados do ponto de vista das relações que se instauram entre a instância da enunciação, responsável pela produção e pela comunicação do discurso, e o texto-enunciado" (BARROS, 2002, p. 11), e as formas mais abstratas no nível narrativo são revestidas de termos concretos por meio de temas e de figuras. Em Haroun e Mar de Histórias, Rashid que estava em conjunção com o objeto palavra (liberdade), entra em disjunção com ele. Essa estrutura pode ser entendida como censura/privação da palavra, tendo em vista que Rushdie, cujo nome se assemelha ao do nosso contador de histórias, deixa alguns vestígios de que seu texto "não era apenas uma história” (RUSHDIE, 1998, p. 63).

Rushdie foi um dos autores mais perseguidos pelo Islã na década de 1990, por conta do romance Versos Satânicos (1988). No ano seguinte à publicação, o aiatolá Ruhollah Khomeini emitiu uma fatwa contra o escritor por fomentar abandono da fé islâmica. Rushdie passa a morar na Inglaterra e, desde então, vive no anonimato. Isso, porém, não o impediu de lançar Haroun e o Mar de História, obra que afirma ser uma tentativa de explicar ao filho o tema da liberdade de expressão. 
Fiorin (1995) enfatiza que as estruturas narrativas podem receber investimentos de duas ordens: temáticos e figurativos e, nesse sentido, tais investimentos correspondem ao enriquecimento semântico do discurso. Nos textos temáticos, prevalecem traços abstratos, que explicam o mundo; por outro lado, nos figurativos, predominam traços semânticos concretos, que simulam o mundo. Uma dissertação ou tese, que tem como tema a liberdade de expressão no contexto do Irã nos anos de 1990, é um texto temático, já um texto que trata dos mesmos assuntos com predominância de figuras, como Haroun e o Mar de Histórias, é um texto figurativo.

Para dar veracidade ao tema liberdade de expressão, Rushdie busca persuadir o enunciatário a aceitar seu discurso, criando um simulacro do mundo. Na narrativa em análise, temos um contador de histórias inserido em um mundo fantástico, instaurando o universo ficcional, em que há Mar de histórias, grandes contadores valorizados pelos políticos, personagens como páginas etc. As histórias contadas remetem a mundos distantes e muito assemelhado às histórias como aquelas contadas em As mil e uma noites.

Por outro lado, Rashid e seu filho se deparam com as mesmas histórias contadas por ele, ou seja, a história dentro da história. Estabelece-se, pois, a metalinguagem e um novo percurso isotópico, que pela inserção de figuras alheias ao contexto narrado, autorizam nova possibilidade de leitura. A partir disso, seu filho tem a seguinte reflexão: “Quantas histórias inventadas estão se transformando em realidade!” (RUSHDIE, 1998, p. 88). Assim como as histórias fantásticas de Rashid se aproximam do mundo deles, a história de Rushdie estabelece uma relação com seu mundo.

Por outro lado, as ideias presentes na obra de Rushdie - que não são apenas de histórias inventadas - são reforçadas a partir da ausência do $e u$ no discurso narrativo, propondo, assim, uma reflexão sobre o papel de tais histórias narradas em $3^{\text {a }}$. pessoa. Isso se torna evidente se notarmos que as falas das personagens aparecem sempre entre aspas. Sabemos que narração em $3^{\mathrm{a}}$. pessoa cria o efeito de sentido de objetividade e recupera a forma de narrar do antigo contador de histórias, que apresenta o narrado com diálogos diretos, porém, pelos traços já apresentados, uma possível leitura é a figurativização da própria história do autor.

“E pra que servem histórias que nem sequer são de verdade?” (RUSHDIE, 1998, p. 16-17), esse trecho impõe o seguinte questionamento sobre se o texto pode ser lido distante da sua relação com a sociedade e, de acordo com Barros (1994, p. 2), ao resgatar as ideias de Bahktin (1895-1975), "Ignorar a natureza dos discursos é o mesmo [...] que apagar a ligação que existe entre a linguagem e a vida", assim entendemos que texto e contexto são indissociáveis e tematizar a liberdade e, especificamente, a liberdade de expressão é evidentemente um tema caro a Rushdie e ela abarca outras questões sobre a palavra e o poder. 
Salvar Batchit, que tolo plano!

O que importa é salvar o Oceano!

Vamos percorrer todo o terreno!

Salvar o Mar é a nossa lei!

O Mar vale mais do que a filha de um rei! (RUSHDIE, 1998, p. 136).

'Que exército!', refletiu Haroun. 'Se algum soldado se comportasse dessa maneira na Terra, seria condenado por uma corte marcial no mesmo instante' [...]. 'Mas mas mas', disse Gavião MasMAs, 'qual é o sentido de se dar às pessoas Liberdade de Expressão, e depois dizer que elas não devem utilizá-las? E não é o Poder da Palavra o maior de todos os Poderes?' (p. 138-139).

Rushdie provoca ainda uma segunda reflexão: até que ponto vai nossa liberdade de expressão? Acreditamos que temos liberdade, mas, ao mesmo tempo, nos identificamos com o pensamento de Haroun e suas dúvidas, pois, ao representar como seria, de fato, um mundo com liberdade de expressão, Rushdie causa esse estranhamento no leitor, da mesma forma que Haroun o manifesta na obra. "E não é a palavra o maior de todos os poderes?" Este é justamente o tema que Rushdie trata: quem controla a informação controla o mundo. Se a liberdade de expressão é controlada, não a temos, portanto, somos controlados. Há, portanto, o binômio palavra e poder.

A liberdade de expressão é o tema que perpassa toda a obra, porém, outro tema pulsa na narrativa: o processo de criação, isto é, a metalinguagem. Essa temática se manifesta por meio de inúmeras figuras que se ordenam de uma forma indissociável, pois a liberdade de expressão implica em um posicionamento pela linguagem.

[...] o Mar de Fios de Histórias era, na verdade, a maior biblioteca do universo. E como as histórias ficavam guardadas ali em forma fluida, elas conservavam a capacidade de mudar, de se transformar em novas versões de si mesmas, de se unirem a outras histórias; de modo que, ao contrário de uma biblioteca de livros, o Mar de Fios de Histórias era muito mais do que um simples depósito de narrativas. Não era um lugar morto, mas sim cheio de vida (RUSHDIE, 1998, p. 82).

Observamos que o Mar de Fios de Histórias era na verdade uma biblioteca e em seu nome há duas figuras, os fios que remetem a tecelagem e as histórias que aludem a textos, narrativas, livros etc. Podemos notar que fios e histórias podem ser entendidos como o ato de tecer textos. Como a biblioteca é figurativizada pelo mar, as histórias são guardadas de forma fluída, o que garante sua capacidade de se modificar. Assim, a metáfora do mar de fios de histórias não se refere apenas ao texto finalizado, mas ao texto em seu processo de criação. Tal possibilidade de leitura pode ainda ser observada quando as relações entre histórias são tematizadas. 
'Quando estão com fome eles engolem histórias por todas as bocas, e lá nas suas entranhas acontece um milagre: um pedacinho de uma história se junta com uma ideia de outra, e pronto! Quando eles cospem as histórias, elas já não são mais as mesmas, antigas; são outras, novas. Nada vem do nada, Ladrãozinho; nenhuma história vem do nada; as histórias novas nascem das velhas. São as novas combinações que fazem com que elas sejam novas' (RUSHDIE, 1998, p. 98-99).

Se o Mar de Histórias diz respeito ao texto em seu processo, os peixes Milbocas representam o próprio ato de criar do autor. De forma análoga, assim como os peixes Milbocas engolem histórias antigas e cospem novas histórias, o autor tece novos textos a partir dos inúmeros fios de histórias que fazem parte de seu repertório. Nesse sentido, em Haroun e o Mar de Histórias, Rushdie não só se assemelha a Rashid, mas também aos peixes Milbocas. Justificamos tal afirmação por meio da forma como constrói sua obra, já que a obra em questão é um apanhado de histórias, mas a referência principal é a célebre Mil e Uma Noites. As inúmeras citações que o príncipe bolo faz das histórias da Mil e Uma Noite, como: Bolo e a Lâmpada Maravilhosa; Bolo e os Quarenta Ladrões; Bolo, o Marujo etc. A casa flutuante que recebe o nome de Mil e Uma Noites, entre outras referências. Então, Rashid engole as inúmeras histórias de seu repertório e cria a complexa obra Haroun e o Mar de Histórias.

\section{CONSIDERAÇÕES FINAIS}

Por meio da análise realizada, foi possível verificar a pertinência da oposição opressão versus liberdade como estruturante do sentido da obra Haroun e o Mar de Histórias, de Salman Rushdie. Enfatizando a relação entre linguagem, sociedade e história, Rushdie constrói uma obra que, além de chamar atenção para o tema da liberdade de expressão, também remete ao processo de criação de histórias e da palavra como forma de poder dentro de uma determinada sociedade. Ambos os temas se entrelaçam e imbricam, já que linguagem e poder são indissociáveis como muitos analistas do discurso apontam (FIORIN, 2004).

A oposição fundamental liberdade versus opressão bem representa essa problemática e Rushdie habilmente soube articulá-la em um texto narrativo fantasioso, mas que metaforiza o processo criador em um contexto de opressão. Ao longo da narrativa, é possível acompanhar os caminhos de um sujeito que sofre pela perda da capacidade de contar - Rashid e em parte em busca da compreensão desse novo mundo que o assusta: Haroun.

O entrecruzar de caminhos dos personagens e os enlaces de diversas histórias que compreendem o universo ficcional são as portas de entrada dessa narrativa-ensinamento, em que há a positivação do lado da liberdade e o questionamento dos seus limites. Inúmeros exemplos ao longo da História nos mostram a relevância de uma discussão como esta proposta por Rushdie 
como e ainda a atualidade de sua produção literária. Entre história real do autor à concretização de uma fábula infantil, Rushdie conduz o leitor a uma reflexão profunda que merece ser lida e estudada.

\section{REFERÊNCIAS}

BAKHTIN, M. Estética da criação verbal. Tradução Maria Ermantina Galvão; rev. trad. Marina Appenzeller. 3. ed. São Paulo: Martins Fontes, 2000.

BARROS, D. L. P. Dialogismo, Polifonia e Enunciação. In: Diana Luz Pessoa de Barros; José Luiz Fiorin (org.). Dialogismo, Polifonia e Intertextualidade em torno de Bakhtin. São Paulo: EDUSP, 1994. p. 1-10.

BARROS, D. L. P. Teoria Semiótica do Texto. 4. ed. São Paulo: Ática, 2002.

BARROS, D. L. P. Estudos do Discurso. In: FIORIN, José Luiz (org.). Introdução à linguistica II: princípios de análise. 4. ed. São Paulo: Contexto, 2008.

FIORIN, J. L. A noção de texto em Semiótica. Organon, Porto Alegre, v. 9, n. 23, p. 163-173, n. 1995.

FIORIN, J. L. Sendas e veredas da semiótica narrativa e discursiva. Revista D.E.L.T.A., v. 15, n. 1, p.177-207, 1999.

FIORIN, J. L. Linguagem e Ideologia. 8. ed. São Paulo. Editora Ática, 2004.

FIORIN, J. L. A linguagem humana: do mito à ciência. In: FIORIN, José Luiz (org.). Linguística? Que é isso? 1. ed. São Paulo: Contexto, 2013. v. 1. p. 13-43.

FIORIN, J. L. O uso linguístico: a pragmática e o discurso. In: FIORIN, José Luiz (org.). Linguística? Que é isso? São Paulo: Contexto, 2013. v. 1. p. 181-203.

RUSHDIE, S. Haroun e o Mar de Histórias. Tradução Isa Mara Lando São Paulo: Companhia das Letras, 1998.

TATIT, L. A abordagem do texto. In: FIORIN, José Luiz (org.). Introdução à linguística. 6. ed. São Paulo: Contexto, 2014. 